\title{
PENINGKATAN KUALITAS CITRA $X$-RAY PARU-PARU PASIEN COVID-19 MENGGUNAKAN METODE CONTRAST LIMITED ADAPTIVE HISTOGRAM EQUALIZATION
}

\author{
Tinaliah $^{1}$, Triana Elizabeth ${ }^{2}$ \\ ${ }^{1}$ Program Studi Manajemen Informatika, AMIK MDP \\ ${ }^{2}$ Program Studi Sistem Informasi, STMIK Global Informatika MDP \\ Jl. Rajawali No. 14, Palembang, Sumatera Selatan 30113 \\ ${ }^{1}$ tinaliah@mdp.ac.id, ${ }^{2}$ trianaelizabeth@mdp.ac.id
}

\begin{abstract}
Covid-19 is currently a pandemic around the world, and until now there has been no specific cure for this disease. An x-ray examination of the lungs is one of the tests that can be done to detect Covid-19. X-ray results must be read carefully to determine whether the patient is really exposed to Covid-19. Improved quality of $\mathrm{x}$-ray images is needed to help doctors or health practitioners see more clearly the x-ray results of the lungs. One of the methods used to improve image quality is CLAHE method. This method is a simple and efficient method to implement, and is able to produce a better image than the original, unprocessed image. Based on the test results, it can be concluded that the CLAHE method can improve the quality of x-ray images of the lungs. The CLAHE method with the Rayleigh distribution has the lowest average MSE value of 0.01474 and has the highest average PSNR value of $18.6642 \mathrm{~dB}$ compared to the Uniform distribution and the Exponential distribution.
\end{abstract}

Keywords - Covid-19, Lung X-ray, Image Enhancement, and CLAHE.

\begin{abstract}
Abstrak - Covid-19 saat ini telah menjadi pandemi di seluruh dunia. Obat khusus untuk penyakit covid-19 sampai saat ini belum ditemukan. Covid-19 dapat dideteksi dengan melakukan pemeriksaan menyeluruh, yaitu salah satunya dengan menggunakan pemeriksaan x-ray paru-paru. Pembacaan hasil x-ray harus dilakukan secara teliti untuk menentukan apakah pasien benar terkena Covid-19. Untuk membantu dokter ataupun praktisi kesehatan dalam lebih jelas untuk melihat hasil x-ray paruparu, maka dibutuhkan peningkatan kualitas citra x-ray agar hasil kualitas citra dapat lebih baik dan lebih jelas dibaca. Metode CLAHE merupakan metode yang dapat digunakan untuk peningkatan kualitas citra. Metode ini merupakan metode yang simpel dan efisien untuk diimplementasi, serta dapat menghasilkan citra yang lebih baik. Berdasarkan hasil pengujian dapat disimpulkan bahwa dengan menerapkan metode CLAHE hasil kualitas citra x-ray paru-paru dapat lebih ditingkatkan. Nilai rata - rata MSE Metode CLAHE dengan distribusi Rayleigh mempunyai nilai rata - rata yang paling rendah sebesar 0.01474, dan mempunyai nilai rata - rata PSNR yang paling tinggi sebesar 38.6642 dB dibandingkan distribusi Uniform dan distribusi Exponential.
\end{abstract}

Kata Kunci - Covid-19, X-ray Paru-Paru, Peningkatan Kualitas Citra, dan CLAHE.

\section{PENDAHULUAN}

Pada awal tahun 2020, seluruh dunia sedang menghadapi pandemi Covid-19. Penyakit ini menular disebabkan oleh jenis coronavirus baru, dan ditemukan pertama kali di kota Wuhan, Tiongkok pada bulan Desember 2019 dan saat ini sudah menjadi pandemi di banyak Negara di seluruh dunia. Obat khusus untuk penyakit covid-19 sampai saat ini belum ditemukan[1].

Penyakit Covid-19 merupakan penyakit yang menyerang pernapasan dikenal sebagai infeksi saluran napas yang parah atau sindrom pernapasan akut. Untuk dapat mendeteksi penyakit Covid-19 pada umumnya dilakukan secara klinis melalui pemeriksaan gejala fisik. Pemeriksaan x-ray paru-paru adalah salah satu contoh pemeriksaan yang dapat dilakukan untuk mendeteksi Covid-19. X-ray ini bertujuan untuk melihat citra paru - paru dan saluran pernafasan. Melalui hasil $x$-ray dapat diketahui apakah pasien mengalami infeksi atau peradangan yang terjadi pada saluran pernafasan dan paru - paru[2].

Dokter atau praktisi kesehatan akan melakukan pengamatan visual dalam pembacaan hasil x-ray paruparu. Pembacaan hasil $\mathrm{x}$-ray harus dilakukan secara teliti, karena banyak sekali jaringan yang tertumpuk dalam hasil x-ray[3]. Dokter atau praktisi kesehatan harus mengeluarkan hasil diagnosis yang benar benar akurat untuk menentukan apakah pasien benar terkena Covid-19.

Untuk membantu dokter ataupun praktisi kesehatan dalam lebih jelas untuk melihat hasil x-ray paru-paru, maka dibutuhkan peningkatan kualitas citra $\mathrm{x}$-ray agar hasil kualitas citra dapat lebih baik lagi dan lebih jelas dibaca.

Saat ini, terdapat banyak sekali penelitian yang sudah membahas mengenai berbagai macam metode yang dapat digunakan untuk peningkatan kualitas citra, Metode Histogram Equalization (HE) adalah salah satu metodenya. Metode ini dapat menghasilkan 
histogram citra yang merata. Kelemahan dari metode ini yaitu melakukan menaikan kontras citra secara global[4]. Metode Contrast Limited Adaptive Histogram Equalization (CLAHE) diusulkan untuk memperbaiki kelemahan dari metode HE. Metode CLAHE merupakan metode yang simpel dan efisien untuk diimplementasi[5].

Penelitian[4] melakukan penerapan metode perengangan kontras dan filtering menggunakan metode CLAHE dan Gaussian filter. Data yang digunakan adalah 20 citra kanker (ber-nodul) yang diambil secara acak pada database JSRT. Percobaan yang dilakukan dalah membandingkan performa dari metode CLAHE dengan metode HE, dan melakukan perbandingan perfoma metode Gaussian Filter dengan metode median filter. Dapat disimpulkan bahwa metode yang digunakan dapat meningkatkan kualitas citra lebih baik dibandingkan dengan menggunakan metode HE dan Median Filter.

Penelitian[6] melakukan perbandingan dari berbagai jenis metode Histogram Equalization pada citra X-ray. Data yang digunakan adalah 10 citra medis x-ray. Percobaan yang dilakukan adalah melakukan peningkatan kualitas citra dengan metode Histogram Equalization (HE), Adaptive Histogram Equalization (AHE), dan Contrast Limited Adaptive Histogram Equalization (CLAHE). Dapat disimpulkan bahwa untuk hasil peningkatan kualitas citra medis $\mathrm{x}$-ray dengan menggunakan metode CLAHE lebih baik dibandingkan dengan metode HE dan AHE.

Penelitian[7] melakukan perbaikan kualitas citra penginderaan jauh dengan membandingkan metode CLAHE dan High-Frequency Emphasis (HFE). Data yang digunakan sebanyak 20 citra SAS-planet dengan format *.jpg (RGB). Percobaan yang dilakukan adalah melakukan perbandingan hasil dua metode, yaitu metode HFE dan metode CLAHE. Dapat disimpulkan bahwa dari 20 citra, metode CLAHE dapat meningkatkan 8 citra, dan ada 4 citra yang mempunyai PSNR diatas $30 \mathrm{~dB}$ dengan menggunakan metode HFE.

\section{A. Covid-19}

Covid-19 adalah jenis penyakit yang menyerang pernapasan dan dikenal sebagai penyakit infeksi saluran pernapasan yang parah atau sindrom pernapasan akut coronavirus[2].

Gejala umum penyakit Covid-19 yang dapat dialami adalah demam, batuk kering, dan rasa lelah, serta gejala lainnya yang mungkin bisa dialami oleh beberapa pasien yaitu rasa nyeri, hidung tersumbat, sakit kepala, sakit tenggorokan, ataupun kehilangan indera perasa atau penciuman. Gejala yang timbul dapat muncul bertahap dan ringan. Beberapa orang yang terinfeksi memiliki gejala ringan dan dapat sembuh tanpa memerlukan perawatan yang intensif[1].

\section{B. Image Enhancement}

Image Enchancement merupakan tahap dalam proses awal pengolahan citra digital (Image Preprocessing). Tahap ini perlu dilakukan karena sering kali citra memiliki kualitas yang kurang baik atau buruk seperti citra mengalami noise (derau), terlalu terang / gelap, kurang tajam, kabur, dll[7].

Dengan proses ini, feature sebuah citra dapat semakin jelas [7].

\section{Histogram Equalization}

Histogram Equalization merupakan metode yang sering digunakan untuk menaikkan nilai kontras sebuah citra mengguakan histogram. Metode ini bertujuan untuk membuat nilai kontras yang kurang menjadi lebih tinggi secara global, sehingga nilainya dapat dapat merata dengan baik sesuai dengan histogramnya[8].

\section{Contrast Limited Adaptive Histogram \\ Equalization (CLAHE)}

Metode CLAHE merupakan modifikasi dari metode Adaptive Histogram Equalization (AHE). Metode ini merupakan metode yang simpel dan efisien untuk diimplementasi. Metode ini dapat memisahkan latar belakang dan latar depan gambar, serta mampu mengurangi noise, dan meningkatkan kontras[5].

Tahapan Metode CLAHE[5], yaitu :

1. Membagi citra asli menjadi sub citra berukuran $M$ $x N$

2. Mengitung histogram sub citra

3. Clipped histogram dari setiap citra.

Distribusi jumlah piksel sub citra pada masing masing derajat keabuan. Rata-rata jumlah piksel sub citra pada masing - masing derajat keabuan dapat dilihat pada persamaan (1)

$$
N_{\text {avg }}=\frac{N_{S I-X P * N_{S I-Y P}}}{N_{\text {graylevel }}}
$$

$$
\begin{aligned}
\text { Keterangan: } & \\
N_{\text {avg }}= & \text { rata-rata jumlah piksel } \\
N_{\text {graylevel }}= & \text { jumlah nilai derajat keabuan } \\
& \text { (gray level) pada sub citra } \\
N_{S I-X P}= & \text { jumlah piksel sub citra pada } \\
& \text { dimensi X } \\
N_{S I-Y P}= & \text { jumlah piksel sub citra pada } \\
& \text { dimensi } Y
\end{aligned}
$$

Cara menghitung clip limit suatu histogram dapat dilihat pada persamaan (2)

$$
N_{C L}=N_{C L I P} * N_{a v g}
$$

Keterangan :

$N_{C L} \quad=$ clip limit 


$$
\begin{aligned}
N_{\text {CLIP }}= & \text { nilai max rata-rata piksel setiap nilai } \\
& \text { derajat keabuaan sub citra }
\end{aligned}
$$

Piksel akan diclipped jika jumlah piksel lebih besar dari $N_{C L I P}$, pada histrogram citra asli. Jumlah piksel akan didistribusikan ke dalam masing - masing derajat keabuan $\left(N_{d}\right)$ dapat dilihat pada persamaan (3)

$$
N_{d}=\frac{N_{T C}}{N_{\text {gray }}}
$$

Cara menghitung Constrast Limited Histogram pada setiap sub citra dapat dilihat pada persamaan (4)

$$
\begin{aligned}
& \text { If } H_{S I}>N_{C L}, H_{N S I}(i)=N_{C L} \\
& \text { Else If } H_{S I}(i)+N_{d} \geq N_{C L}, H_{N S I}(i)=N_{C L}(4) \\
& \text { Else } H_{N S I}(i)=H_{S I}(i)+N_{d}
\end{aligned}
$$

Tahap distribusi piksel dapat dilihat pada persamaan (5)

$$
S=\frac{N_{\text {graylevel }}}{N_{R P}}
$$

Keterangan :

$N_{R P} \quad=$ sisa dari jumlah piksel yang dipotong

Selanjutnya metode ini akan menelusuri semua piksel dari tingkat minimum sampai tingkat maksimum derajat keabuan, dan akan didistrubusikan satu piksel nilai derajat keabuan tersebut, jika ditemukan frekuensi piksel derajat keabuan yang lebih kecil dari $N_{C L}$. Pencarian akan terus dilakukan sampai semua piksel berhasil terdistribusi. Tahap distribusi piksel akan dihitung lagi untuk pencarian yang selesai sebelum dilakukan pendistribusian semua piksel berdasarkan persamaan (5).

4. Pemetaan piksel setiap gambar dengan menggunakan interpolasi linear. Histogram setiap sub citra akan diproses dengan menggunakan Histogram Equalization.

\section{E. Mean Square Error (MSE)}

MSE adalah metode yang digunakan untuk mengukur kontrol dan kualitas sebuah citra. Nilai MSE dihitung dengan cara membandingkan sebuah objek contoh dengan objek aslinya, sehingga bisa diketahui tingkat ketidaksesuaiannya[9].

Nilai MSE yang dihasilkan apabila semakin rendah dan mendekati 0 (nol), maka akan semakin semakin mirip dengan citra aslinya dan bagus kualitas citra tersebut[7].
F. Peak Signal Noise Ratio (PSNR)

PSNR adalah metode yang digunakan untuk mengukur sistem rekonstruksi resolusi gambar. Semakin besar nilai PSNR yang dihasilkan, maka kualitas gambar akan semakin baik dan memiliki PNSR diatas 30dB[7, 9].

\section{METODE PENELITIAN}

Metode penelitian digunakan untuk menjelaskan beberapa tahapan yang akan dilakukan. Metode yang digunakan adalah metode penelitian secara eksperimental. Tahap pengembangan sistem dilakukan, yaitu :

1. Tahap Studi Literatur

Pada tahap ini dilakukan pengumpulan data yang dibutuhkan dalam penelitian ini mengenai peningkatan kualitas citra $\mathrm{X}$-ray paru-paru pasien Covid-19 dengan menggunakan metode CLAHE. Data yang dikumpulkan dengan cara mengumpulkan informasi dari berbagai sumber yang ada. Tahapan ini dilakukan dengan tujuan agar dapat lebih memahami mengenai materimateri yang akan digunakan pada topik ini dan menambah wawasan, sehingga dapat dijadikan dasar yang kuat dalam penelitian ini.

\section{Tahap Perancangan}

Pada tahap ini dilakukan perancangan sistem yang akan dibangun, yaitu perancangan aplikasi peningkatan kualitas citra $\mathrm{X}$-ray paru-paru pasien Covid-19 dengan metode CLAHE, dan proses persiapan data yang akan digunakan.

3. Tahap Implementasi dan Pengujian

Pada tahap ini dilakukan implementasi dari sistem yang telah dirancang ke dalam bentuk aplikasi, lalu dilakukan pengujian dari aplikasi yang telah dibuat.

4. Tahap Analisis hasil pengujian

Pada tahap ini dilakukan analisis dari hasil pengujian yang telah dilakukan untuk menjawab masalah dari penelitian. Dari hasil analisis ini dapat ditarik kesimpulan mengenai hasil peningkatan kualitas citra X-ray paru-paru pasien Covid-19 menggunakan metode CLAHE.

\section{HASIL DAN PEMBAHASAN}

Data citra yang digunakan adalah citra $\mathrm{x}$-ray paruparu pasien Covid-19 berjumlah 15 buah citra RGB dengan format*.jpg yang diperoleh dari situs github.com[10].

Setiap citra akan dilakukan tahap preprocessing yaitu membuang bagian hitam citra hasil x-ray, dan mengubah citra asli menjadi citra grayscale.

Proses pada metode CLAHE akan dilakukan pada citra grayscale $\mathrm{x}$-ray paru-paru. Pada metode CLAHE 
ini akan menggunakan 3 (tiga) distribusi, yaitu: Distribusi Uniform, Distribusi Rayleigh, dan Distribusi Exponential. Hasil perbandingan citra x-ray asli dengan citra hasil metode CLAHE Distribusi Uniform, Rayleigh, dan Exponential dapat dilihat pada gambar 1.

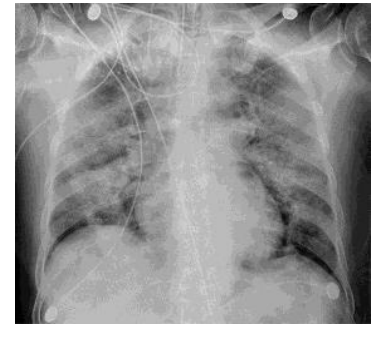

(a) Citra X-ray Asli

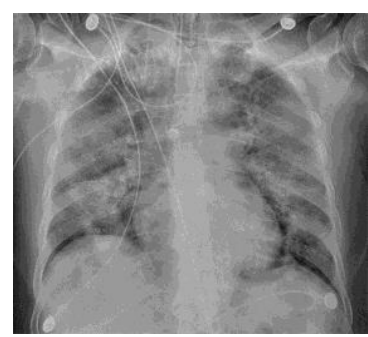

(c) Citra X-ray

Metode CLAHE

Distribusi Rayleigh

Gambar 1. Hasil Perbandingan Ci dengan Citra Hasil Metode CLAHE

Hasil perbandingan histogram citra X-ray paruparu asli dengan citra hasil hasil metode CLAHE Distribusi Uniform, Rayleigh, dan Exponential dapat dilihat pada gambar 2 .

(a) Distribusi Citra Asli

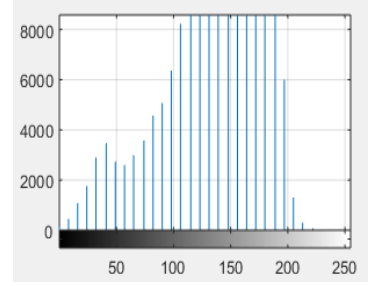

(c) Distribusi Rayleigh
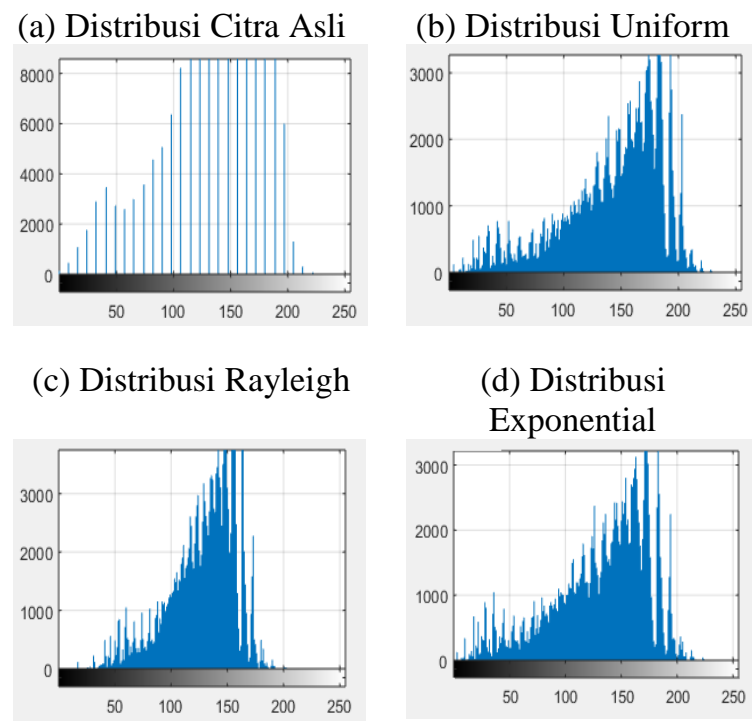

(d) Distribusi

Exponential

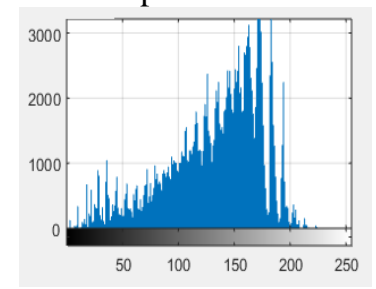

Gambar 2. Hasil Perbandingan Histogram Citra Asli dengan Citra Hasil Metode CLAHE
Untuk menilai citra hasil metode CLAHE dengan Distribusi Uniform, Rayleigh, dan Eksponential secara objektif, maka digunakan pengukuran dengan MSE dan PSNR untuk mengukur tingkat keberhasilan metode CLAHE[4]. Hasil pengukuran MSE dan PSNR terdapat pada tabel 1 dan tabel 2 .

Tabel 1. Hasil Pengukuran Nilai MSE

\begin{tabular}{|c|c|c|c|}
\hline \multirow{2}{*}{ Citra } & \multicolumn{3}{|c|}{ Distribusi } \\
\cline { 2 - 4 } & Uniform & Rayleigh & Exponential \\
\hline 1 & 0.01916 & 0.01863 & 0.02510 \\
\hline 2 & 0.01147 & 0.01187 & 0.01340 \\
\hline 3 & 0.01299 & 0.01842 & 0.01867 \\
\hline 4 & 0.01797 & 0.01578 & 0.01814 \\
\hline 5 & 0.01014 & 0.01019 & 0.01256 \\
\hline 6 & 0.01911 & 0.01310 & 0.01520 \\
\hline 7 & 0.01695 & 0.01566 & 0.01788 \\
\hline 8 & 0.01038 & 0.00950 & 0.01088 \\
\hline 9 & 0.01725 & 0.02696 & 0.02510 \\
\hline 10 & 0.01986 & 0.01319 & 0.01480 \\
\hline 11 & 0.01128 & 0.01420 & 0.01296 \\
\hline 12 & 0.01563 & 0.01694 & 0.01794 \\
\hline 13 & 0.01284 & 0.01346 & 0.01112 \\
\hline 14 & 0.00763 & 0.00763 & 0.00763 \\
\hline 15 & 0.02679 & 0.01558 & 0.01969 \\
\hline Rata-Rata & $\mathbf{0 . 0 1 5 3 0}$ & $\mathbf{0 . 0 1 4 7 4}$ & $\mathbf{0 . 0 1 6 0 7}$ \\
\hline
\end{tabular}

Tabel 2. Hasil Pengukuran Nilai PSNR

\begin{tabular}{|c|c|c|c|}
\hline \multirow{2}{*}{ Citra } & \multicolumn{3}{|c|}{ Distribusi } \\
\cline { 2 - 4 } & Uniform & Rayleigh & Exponential \\
\hline 1 & 37.1767 & 37.2990 & 36.0034 \\
\hline 2 & 39.4040 & 39.2549 & 38.7288 \\
\hline 3 & 38.8649 & 37.3466 & 37.2880 \\
\hline 4 & 37.4544 & 38.0178 & 37.4141 \\
\hline 5 & 39.9384 & 19.9167 & 39.0111 \\
\hline 6 & 37.1877 & 38.8270 & 18.1812 \\
\hline 7 & 37.7077 & 38.0535 & 17.4769 \\
\hline 8 & 39.8374 & 40.2247 & 39.6342 \\
\hline 9 & 37.6335 & 35.6922 & 36.0039 \\
\hline 10 & 37.0199 & 38.7986 & 38.2967 \\
\hline 11 & 39.4766 & 38.4778 & 38.8739 \\
\hline 12 & 38.0599 & 37.7103 & 37.4627 \\
\hline 13 & 38.9161 & 38.7112 & 39.5410 \\
\hline 14 & 41.1769 & 43.5598 & 42.0953 \\
\hline 15 & 35.7205 & 38.0736 & 37.0577 \\
\hline Rata-Rata & $\mathbf{3 8 . 3 7 1 6}$ & $\mathbf{3 8 . 6 6 4 2}$ & $\mathbf{3 8 . 2 0 4 6}$ \\
\hline
\end{tabular}

Pengujian yang dilakukan bertujuan untuk mengetahui hasil perbandingan kualitas citra X-ray asli dengan citra hasil metode CLAHE Distribusi Uniform, Rayleigh, dan Exponential dengan melakukan pengukuran MSE dan PSNR.

Berdasarkan hasil pengujian, dapat ditarik kesimpulan bahwa rata-rata nilai MSE untuk distribusi 
Rayleigh mempunyai nilai rata-rata MSE yang paling rendah sebesar 0.01474 dibandingkan nilai rata-rata MSE untuk distribusi Uniform sebesar 0.01530 dan distribusi Exponential sebesar 0.01607. Nilai MSE yang dihasilkan apabila semakin rendah dan mendekati 0 (nol), maka akan semakin semakin mirip dengan citra aslinya dan bagus kualitas citra tersebut[7].

Rata-rata nilai PSNR untuk distribusi Rayleigh merupakan nilai yang paling tinggi, yaitu sebesar $38.6642 \mathrm{~dB}$ dibandingkan nilai PSNR untuk distribusi Uniform sebesar $38.3716 \mathrm{~dB}$ dan Exponential sebesar $38.2046 \mathrm{~dB}$

\section{KESIMPULAN}

Berdasarkan hasil pengujian pada penelitian ini penulis dapat menyimpulkan bahwa :

1. Metode CLAHE dapat digunakan untuk peningkatan kualitas citra $\mathrm{X}$-ray paru-paru pasien Covid-19 ditunjukan dengan penyebaran histogram yang lebih merata.

2. Metode CLAHE dengan distribusi Rayleigh mempunyai perfoma yang lebih baik dibandingkan dengan menggunakan distribusi Uniform dan distribusi Exponential dalam hal peningkatan kualitas citra.

\section{DAFTAR PUSTAKA}

[1] WHO, "Coronavirus" 2020, [Online]. Tersedia: $\quad$ https://www.who.int/healthtopics/coronavirus\#tab=tab_1, [Diakses 1 November 2020].

[2] M. Ghozali, and H. Sumarti, "Deteksi Tepi Pada Citra Rontgen Penyakit COVID-19 Menggunakan Metode Sobel," Jurnal Imejing Diagnostik, pp. 51- 59, 2020.

[3] L. Listyalina, "Peningkatan Kualitas Citra Foto Rontgen Sebagai Media Deteksi Kanker Paru," J. Teknol. Inf., vol. 7, no. 34, pp. 110-118, 2017.

[4] M. M. Sebatun, "Peningkatan Kualitas Citra X-ray Paru-Paru Menggunakan Contrast Limited Adaptive Histogram Equalization Dan Gaussian Filter," Semin. Ris. Teknol. Inf., pp. 241-247, 2016.

[5] C. Ramya, and S. Subha Rani, "A Novel Method For The Contrast Enhancement of Fog Degraded Video Sequences," Int. J. Comput. Appl., vol. 54, no. 13, pp. 1-5, 2012.

[6] A. A. Riadi, A. A. Chamid, and A. Sokhibi, "Analisis Komparasi Metode Perbaikan Kontras Berbasis Histogram Equalization Pada Citra Medis," Simetris J. Tek. Mesin, Elektro dan Ilmu Komput., vol. 8, no. 1, pp. 383-388, 2017.

[7] A. I. Zakaria, E. Ernawati, A. Vatresia and W. K. Oktoeberza, "Perbandingan Metode High-
Frequency Emphasis (HFE) Dan Contrast Limited Adaptive Histogram Equalization (CLAHE) Dalam Perbaikan Kualitas Citra Penginderaan Jauh (Remote Sensing)," Jurnal Pseudocode., vol. 6, no. 2, pp. 125-137, 2019.

[8] Y. N. Nabuasa, "Pengolahan Citra Digital Perbandingan Metode Histogram Equalization Dan Spesification Pada Citra Abu-Abu," J. I. Komputer, U. N. Cendana, C. Digital, and E. Histogram, vol. 7, no. 1, pp. 87-95, 2019.

[9] H. Beni, "Analisa Bicubic Dan Bilinear Menggunakan Metode Discrete Wavelet Transform Pada Super Resolusi," 2014.

[10] J. Paul Cohen, P. Morrison, and L. Dao, "COVID-19 Image Data Collection," arXiv, 2020. 